\title{
O gênero da discórdia. A Igreja Católica e a campanha contra os direitos das mulheres na politica internacional: uma abordagem a partir das conferências do Cairo e de Pequim
}

The gender of disagreement. The Catholic Church and the Campaign against the women`s rights in the international politics

Sandra Duarte de Souza ${ }^{1}$

\section{Resumo}

A ênfase na necessidade do empoderamento das mulheres marcou as Conferências Mundiais sobre a Mulher organizadas pela ONU, em especial a Conferência de Pequim, em 1995, que redimensionou o debate sobre o tema adotando o conceito de gênero e, dessa forma, explicitando o caráter estruturado e estruturante da dominação das mulheres. Apesar de trazer importantes avanços para o debate sobre a desigualdade entre homens e mulheres, a adoção de gênero pela Conferência de Pequim, e também, um ano antes, em 1994, pela conferência do Cairo sobre População e Desenvolvimento, não foi posição unânime, tendo gerado tensionamentos registrados nas reservas apresentadas pelas delegações de diferentes países. A Santa Sé foi uma das protagonistas nesse debate, afirmando oposição aos direitos sexuais e reprodutivos das mulheres, e reagindo fortemente ao conceito de gênero adotado nas conferências da ONU. O presente artigo retoma os temas fundamentais que foram objeto de "reserva" da Santa Sé nas conferências do Cairo e de Pequim, e a política antigênero presente em escritos daquele período que têm servido aos propósitos político-religiosos da Igreja Católica e de outros segmentos de cunho conservador. Os escritos que compõem nosso corpus de análise são os relatórios das conferências do Cairo e de Pequim; "O Evangelho perante a desordem Mundial", de Michel Schooyans; e a nota da Conferência Episcopal do Peru, intitulada La ideologia de género: sus peligros y alcances, elaborada pelo monsenhor Óscar Alzamora Revoredo.

Palavras-chave: Gênero; Igreja Católica; Direitos das Mulheres; ONU

\section{Abstract}

The emphasis in the need of women's empowerment stamped/defined the World Conferences of Women organized by UNO, especially the Beijing conference, in 1995, which redimensioned the debate about the theme adopting the gender concept and, in this way, clarifying the structured and structurant character of

\footnotetext{
${ }^{1}$ Doutora em Ciências da Religião, professora do Programa de Pós-Graduação em Ciências da Religião na Universidade Metodista de São Paulo e coordenadora do Grupo de Estudos de Gênero e Religião Mandrágora/Netmal. E-mail: sanduarte3@gmail.com
} 
Religare, ISSN: 19826605, v.15, n.2, dezembro de 2018, p.483-504.

women's domination. In spite of bringing important advances for the debate on the inequality between men and women, the adoption of gender by the Beijing Conference and also, one year before, in 1994, by the Cairo Conference on Population and Development, it was not a unanimous position, having generated tensioning registered in the reserves presented by delegations of different countries. The Holy See was one of the leading figures in this debate, affirming opposition to the sexual and reproductive rights of women, , thoroughly reacting to the gender concept adopted by the UNO conferences. The present article retakes the fundamental themes which were object of "reserve" from the Holy See in the conferences of Cairo and Beijing and the anti-gender politics in writings of that time which has served to the politic-religious purposes of the Catholic Church and of other segments of conservative nature. The writings that constitute our corpus of analysis are the reports of the conferences in Cairo and Beijing; "The Gospel confronting world disorder" by Michel Schooyans; and the note of the Episcopal Conference of Peru, entitled Gender ideology: its dangers and outreaches, prepared by Monsignor Óscar Alzamora Revoredo.

Keywords: Gender; Catholic Church; Women's Right; United Nations.

Desde 1975 a Organização das Nações Unidas promoveu quatro conferências mundiais voltadas especificamente para o debate e a proposição de políticas para as mulheres, visando o combate às desigualdades de gênero que inviabilizam a participação plena das mulheres na sociedade e as expõem a inúmeras situações de risco. As conferências foram convocadas pela Assembleia Geral da ONU e objetivavam reunir a comunidade internacional para traçar planos e ações para o enfrentamento às desigualdades entre homens e mulheres.

As metas estabelecidas foram as seguintes: plena igualdade de gênero $e$ eliminação da discriminação de gênero; integração e plena participação das mulheres no desenvolvimento; incremento da contribuiç̧ão das mulheres para o reforço da paz mundial. (UN WOMEN, 2000)

A Cidade do México abrigou a primeira conferência em 1975. Em 1980 Copenhagen sediou a segunda conferência, e Nairobi foi o lugar de realização da terceira conferência, em 1985. Os eventos reuniram lideranças de mais de uma centena de países visando empenhar esforços da comunidade internacional na busca de assegurar igualdade de direitos para as mulheres em todos os aspectos, 
Religare, ISSN: 19826605, v.15, n.2, dezembro de 2018, p.483-504.

dentre os quais, igualdade de acesso à educação, à saúde, ao trabalho, à participação política, etc.

A organização de conferências para tratar desses temas e de tantos outros, não se deu descolada da emergência dos movimentos de mulheres em todo o mundo, especialmente em países ocidentais, com maior ou menor força.

Os impactos dessa iniciativa foram positivos, mas insuficientes para a eliminação das desigualdades abissais entre mulheres e homens em quase todo o mundo². O protagonismo das mulheres nos debates e elaboração das plataformas de ação das conferências organizadas pela ONU, especialmente na década de 1990, constrangeu lideranças de diferentes países, acostumadas a decidirem os rumos da humanidade sem considerá-las como sujeitos. Esse foi um período de forte movimentação das mulheres e de organizações feministas na luta pela adoção do gender mainstreaming na agenda internacional (BARSTED, Leila e HERMAN, Jacqueline, 1999). Em outras palavras, a realização das conferências mundiais possibilitou a inclusão de gênero na pauta política internacional, mas não sem grande esforço para a construção de consenso em torno dessa questão.

Uma década depois da Terceira Conferência ocorrida em Nairobi, foi realizada, em 1995, a IV Conferência Mundial sobre as Mulheres, desta vez em Pequim, e após um balanço, se concluiu que as ações mundiais pela igualdade não foram suficientes para mudar a estrutura básica da desigualdade no relacionamento entre homens e mulheres (UN WOMEN, 2000). A ênfase na necessidade do empoderamento das mulheres marcou essa conferência, que redimensionou o debate sobre o tema fazendo uso do conceito de gênero e explicitando seu caráter relacional:

A principal transformação que ocorreu em Pequim foi $o$ reconhecimento da necessidade de mudar o foco das mulheres para o conceito de gênero, reconhecendo que toda a estrutura da

\footnotetext{
2 A respeito da desigualdade de gênero no mundo, verificar o Gender Inequality Index, no Human Development Reports (UNITED NATIONS DEVELOPMENT PROGRAMME, 2018).
} 
Religare, ISSN: 19826605, v.15, n.2, dezembro de 2018, p.483-504.

sociedade, e todas as relações entre homens e mulheres dentro dela, tinham que ser reavaliadas. Somente por meio dessa reestruturação fundamental da sociedade e de suas instituições as mulheres poderiam ser plenamente empoderadas para tomar $\mathrm{o}$ seu lugar de direito como parceiras iguais aos homens em todos os aspectos da vida. Essa mudança representou uma forte reafirmação de que os direitos das mulheres eram direitos humanos e que a igualdade de gênero era uma questão de interesse universal, beneficiando a todos e todas. (UN WOMEN, 2000)

Tomar gênero como diretriz para reavaliar a estrutura social, implica reestruturação das próprias instituições, de tal forma que a generificação das instituições, a desigualdade estruturada e estruturante, é colocada em questão e é desconstruída, viabilizando a equidade entre todos os sujeitos sociais.

Apesar de trazer importantes avanços para o debate sobre a desigualdade entre homens e mulheres, a adoção de gênero pela Conferência de Pequim não foi posição unânime, tendo gerado tensionamentos registrados de uma ou outra forma nas reservas apresentadas pelas delegações de diferentes países. A Santa Sé foi uma das protagonistas nesse debate, afirmando oposição aos direitos sexuais e reprodutivos das mulheres, apresentando reservas em relação a todos os parágrafos dos relatórios do Cairo e de Pequim que tratavam desse tema e reagindo fortemente ao conceito de gênero adotado nas conferências da ONU, se manifestando pública e documentalmente sobre o "perigo da ideologia de gênero" que se traduzia como ameaça para a família, para a sociedade e para a religião.

\section{A Plataforma do Cairo e as "reservas" religiosas}

As resistências observadas na Conferência de Pequim não podem ser descoladas do que ocorreu nas conferências sobre População e Desenvolvimento ocorridas em Bucarest (1974), no México (1984) e no Cairo (1994). Nessas conferências, o enfoque foi especialmente nos direitos reprodutivos das mulheres e no combate à desigualdade de gênero. A Santa Sé não aderiu ao consenso nas conferências de Bucarest (NACIONES UNIDAS, 1975) e do México (CONSEJO 
Religare, ISSN: 19826605, v.15, n.2, dezembro de 2018, p.483-504.

NACIONAL DE POBLACIÓN, 1984), rejeitando todas as referências a aborto e formas de controle de natalidade consideradas "não naturais" pelo Vaticano, diga-se, pela Igreja Católica.

$\mathrm{Na}$ Conferência Internacional sobre População e Desenvolvimento (CIPD), em 1994 no Cairo, as dissonâncias a respeito de temas que envolvem direitos reprodutivos e sexuais novamente apareceram. Naquela ocasião, foram estabelecidas três metas que deveriam ser atingidas até 2015: educação para todas as pessoas, com especial ênfase nas meninas, que são as que têm menos acesso a esse direito fundamental; a redução da mortalidade materna e infantil; e a garantia dos direitos reprodutivos, incluindo acesso a serviços de saúde reprodutiva e planejamento familiar. Na apresentação da publicação organizada por Heloisa Frossard, intitulada Instrumentos Internacionais de Direitos das Mulheres (2006, p. 35), na qual está contido o relatório da CIPD, Tânia Patriota afirma:

\begin{abstract}
Apesar dos avanços alcançados, as conquistas do Cairo não aconteceram sem resistências. Atualmente, segundo o UNFPA, existem dois grandes obstáculos que devem ser superados para que as metas do Cairo sejam atingidas: o aporte insuficiente de recursos e o movimento crescente de setores conservadores, contrários aos princípios acordados em $1994^{3}$.
\end{abstract}

A Plataforma do Cairo gerou reações de grupos conservadores, marcadamente de tradição judaico-cristã e islâmica, especialmente no que se refere à sua ênfase na garantia dos direitos reprodutivos das mulheres. Conforme assinala Lindgren Alves (1996, 71-72), no Cairo

O escarcéu foi provocado (...) pela onda de integrismos que tem caracterizado o período atual. As objeções da Santa Sé não eram novas; já haviam sido formuladas nas conferências anteriores sobre o tema da população, em Bucareste, em 1974, e no México, em 1984. Diziam respeito não somente às referências ao aborto que em nenhum dos casos visava recomendar sua legalização

\footnotetext{
${ }^{3}$ Grifo nosso.
} 
Religare, ISSN: 19826605, v.15, n.2, dezembro de 2018, p.483-504.

generalizada, mas sim encará-lo como um fato e um problema de saúde pública -, mas também a qualquer forma de controle "não natural" da natalidade. Aos países muçulmanos integristas soavam provocativas tanto as propostas atinentes à sexualidade, quanto as recomendações sobre a igualdade de direitos entre os gêneros, uma vez que as leis corânicas estabelecem distinções assumidas no tratamento de homens e mulheres no direito civil, no direito penal e nas sucessões. Essas objeções, a que se uniam os questionamentos judaicos integristas - não incorporados pela delegação de Israel - ainda mais "puritanos" do que os do Islã e do Cristianismo, geraram a impressão de que a Conferência do Cairo seria um exercício anti-religioso, e a interpretação de que as três grandes religiões monoteístas a ela se opunham.

Apesar de o documento do Cairo ressalvar que o Programa de Ação será estabelecido "com pleno respeito aos diferentes valores religiosos e éticos e à formação cultural" (Heloisa FROSSARD, 2006, p. 42), países de diferentes tradições religiosas se manifestaram a esse respeito com reservas. Esse foi o caso da delegação de Brunei Darussalam, país localizado no sudeste asiático e de tradição islâmica, que se pronunciou contrariamente aos parágrafos 7.3, 7.47 e 13.14 que dispõem sobre planejamento familiar, saúde reprodutiva, educação sexual, prevenção de doenças sexualmente transmissíveis com distribuição de preservativos (FROSSARD, 2006, p. 125). O representante alegou que as orientações do Programa de Ação em relação a esses parágrafos, contradizem a lei islâmica e a legislação do país.

A Jordânia, também de tradição islâmica foi enfática ao afirmar que a legislação nacional jordaniana deve ser respeitada, e que por esse motivo, os capítulos do Programa de Ação concernentes à "Igualdade dos sexos, equidade e empoderamento das mulheres"; "Família, seus papéis, direitos, composição e estrutura"; "Crescimento e estrutura da população"; e "Direitos de reprodução e saúde reprodutiva", devem ser aplicados no país de acordo com a sharia islâmica (FROSSARD, 2006, p. 127). A delegação do Kwait fez a mesma ressalva, afirmando o apoio do governo às políticas indicadas na Plataforma do Cairo, desde que não se oponham à sharia islâmica (FROSSARD, 2006, p. 127). 
Religare, ISSN: 19826605, v.15, n.2, dezembro de 2018, p.483-504.

Outros países de tradição islâmica se posicionaram de maneira semelhante. A Líbia declarou suas reservas pautadas na sharia. O representante se referiu à contradição das leis islâmicas presente no documento do Cairo, especificamente no parágrafo 4.17 sobre a equidade entre meninas e meninos, em especial sobre o direito equitativo à herança ${ }^{4}$ (FROSSARD, 2006, p. 127). Foi declarada reserva também em relação ao parágrafo 8.31, que enfatiza a importância do investimento dos governos em políticas de educação sexual e promoção do comportamento sexual seguro e responsável. A restrição a termos como "gravidez indesejada" e "aborto", presentes no Parágrafo 8.25, também foi apontada. O representante do Iêmen pontuou os mesmos aspectos (FROSSARD, 2006, p. 129). Os representantes dos Emirados Árabes Unidos também se posicionaram contrários ao tratamento do aborto como forma de planejamento familiar, bem como não cederam à orientação da equidade no direito à herança, fazendo referência, mais uma vez, à sharia islâmica (FROSSARD, 2006, p. 129).

El Salvador, país latino-americano de maioria católica, apelando para a identidade cristã do continente, apresentou reservas quanto aos direitos reprodutivos, em especial quanto ao aborto, negando esse procedimento como serviço ou método de controle de fecundidade. O país se posicionou também contra a expressão "várias formas de família", presente no documento, afirmando que a sua Constituição não reconhece outra união que não seja entre um homem e uma mulher (FROSSARD, 2006, p. 125-126).

O mesmo posicionamento teve a delegação de Honduras, também de maioria católica. Mais uma vez a restrição ao aborto, à expressão "término da gravidez" e ao reconhecimento de uniões de pessoas do mesmo sexo aparece nas reações (FROSSARD, 2006, p. 126-127).

Outros países latino-americanos seguiram o mesmo caminho que El Salvador e Honduras, conforme podemos verificar no relatório da CIPD reproduzido por FROSSARD (2006). A delegação da Nicarágua declarou reserva

\footnotetext{
${ }^{4}$ A Sura 4:11 do Alcorão dispõe que o homem tem direito ao dobro da herança dada à mulher.
} 
Religare, ISSN: 19826605, v.15, n.2, dezembro de 2018, p.483-504.

quanto aos termos "aborto" e "término da gravidez", e também afirmou que a essência da família está na união entre homem e mulher, opondo-se a quaisquer referências a pessoas do mesmo sexo como "casais" (p. 127-128). Essas restrições apareceram também nas representações do Paraguai ( p. 128), da Argentina (p. 129-130), do Equador (p. 130-131), da Guatemala (p. 131) e da República Dominicana (130). No Peru as reservas apresentadas se referiram especificamente ao aborto (p. 135). Em relação a esse tema, todos os representantes apelaram para o argumento de que "toda pessoa tem o direito fundamental e inalienável à vida e de que esse direito tem início no momento da concepção", fazendo menção ao Capítulo II, artigo $4^{\circ}$. da Convenção Americana de Direitos Humanos, ou à sua própria Constituição.

De todas as representações na Conferência Internacional sobre População e Desenvolvimento, a Santa Sé foi a que apresentou mais reservas, não aderindo ao consenso em relação a diferentes partes do Programa de Ação (FROSSARD, 2006, p. 132-134). Mesmo assim, considerando sua intransigência nas conferências de Bucarest e do México, no Cairo a Santa Sé demonstrou-se um pouco mais aberta ao diálogo, não deixando, porém de se alinhar com outras delegações que apresentaram argumentos de cunho religioso conservador para afirmar suas restrições. Seus representantes fizeram reservas gerais aos Capítulos VII (Direitos de Reprodução e Saúde Reprodutiva), VIII (Saúde, Morbidade e Mortalidade), XI (População, Desenvolvimento e Educação), XII (Tecnologia, Pesquisa e Desenvolvimento), XIII (Ação Nacional), XIV (Cooperação Internacional), XV (Parceria com o Setor Não Governamental) e XVI (Acompanhamento da Conferência).

O aborto foi um tema absolutamente rejeitado pela representação da Santa Sé, e termos como saúde sexual, direitos sexuais, saúde reprodutiva e direitos de reprodução foram aceitos desde que entendidos de acordo com as "normas morais", entenda-se aqui, aquelas estabelecidas pela Igreja Católica. Em relação à anticoncepção, planejamento familiar, controle da fecundidade pelas próprias mulheres, direitos sexuais e reprodutivos, a delegação também enfatizou que 
Religare, ISSN: 19826605, v.15, n.2, dezembro de 2018, p.483-504.

a adesão da Santa Sé ao consenso de modo algum deve ser interpretada como constituindo uma mudança de sua conhecida posição concernente àqueles métodos de planejamento familiar que a Igreja Católica considera moralmente inaceitáveis ou sobre serviços de planejamento familiar que não respeitem a liberdade dos cônjuges, a dignidade humana e os direitos humanos das pessoas interessadas. (...) Com referência ao termo "casais e indivíduos" a Santa Sé reserva sua posição com o entendimento de que essa expressão deve significar casais casados e o homem e a mulher individual que constituem o casal. (Heloisa FROSSARD, 2006, p. 133-134)

O conservadorismo moral deu a tônica do debate sobre a Plataforma de Ação da Conferência do Cairo. As disputas se deram em torno de temas como direitos reprodutivos e sexuais, família, desigualdade de gênero dentre outros. $\mathrm{O}$ consenso ocorreu, porém de forma frágil, e isso seria explicitado nos anos seguintes, com o movimento de diferentes países e com a agência da Igreja Católica para obstaculizar a agenda do Cairo e de Pequim.

\section{A Conferência de Pequim e a adoção do conceito de gênero}

Em 1995, em Pequim, na China, foi realizada a IV Conferência Mundial sobre as Mulheres. A ênfase dessa Conferência foi o empoderamento das mulheres trazendo o conceito de gênero para o centro do debate. $\mathrm{O}$ uso do conceito de gênero foi adotado pela Conferência de Pequim, sob o argumento de que ele permitiria uma compreensão mais abrangente da dinâmica que envolve “a produção social das atividades e da distribuição entre homens e mulheres dos recursos sociais, econômicos e também simbólicos" (FAVIER, 2012, p. 5).

A Declaração de Pequim afirmou o compromisso dos governos dos países signatários de implementar a plataforma de ação e garantir que todas as políticas governamentais sejam elaboradas considerando a perspectiva de gênero (Heloisa FROSSARD, 2006, p. 154). O relatório de Pequim se refere a gênero 222 vezes, sinalizando para a importância atribuída a esse conceito emergente em sua ênfase na complexidade que envolve as desigualdades entre homens e mulheres, 
Religare, ISSN: 19826605, v.15, n.2, dezembro de 2018, p.483-504.

desigualdades baseadas em representações naturalizantes e binárias de um feminino e um masculino paradigmático e hierarquicamente estabelecido. $\mathrm{O}$ documento chamou a atenção para a importância dos países assumirem os direitos humanos das mulheres sem reservas. A grande quantidade de reservas apresentadas à Plataforma do Cairo, sendo uma parte significativa de caráter religioso, indicava as muitas dificuldades de sua implementação em diferentes países de diferentes continentes. Na Declaração de Pequim, no quesito intitulado “Direitos Humanos da Mulher”, o parágrafo 218 adverte:

Para proteger os direitos humanos da mulher é necessário que, na medida do possível, se evite recorrer a reservas ou a formular reservas incompatíveis com o objetivo e o propósito da Convenção, ou incompatíveis de qualquer modo com o direito internacional dos tratados. Se os direitos humanos das mulheres, tal como definidos nos instrumentos internacionais de direitos humanos, não forem plenamente reconhecidos e efetivamente protegidos, aplicados, implementados e cumpridos na legislação e nas práticas nacionais, os códigos de família, civis, penais, trabalhistas e comerciais, assim como as normas e os regulamentos administrativos existirão apenas no papel (ONU MULHERES, 1995, p. 224).

A declaração também foi explícita quanto às influências da religião na perpetuação da violência de gênero, afirmando como dever dos governos a condenação da violência contra as mulheres e a não invocação de "qualquer costume, tradição ou consideração de caráter religioso para furtar-se a suas obrigações com respeito à eliminação da violência, conforme determina a Declaração sobre a Eliminação da Violência contra a Mulher" (ONU MULHERES, 1995, p. 191). Isso vai reaparecer no quesito relativo à eliminação de "atitudes e práticas culturais prejudiciais às meninas", que demanda dos governos a adoção de medidas "para que as tradições, a religião e suas manifestações não constituam causa de discriminação contra as meninas" (ONU MULHERES, 1995, p. 244). 
Religare, ISSN: 19826605, v.15, n.2, dezembro de 2018, p.483-504.

A agenda estava posta e talvez nunca estivemos tão próximos de um consenso mundial para a redução das assimetrias de gênero. A articulação de grupos conservadores contrários às plataformas de ação da Conferência do Cairo e da Conferência de Pequim demonstrou, porém, que o consenso não prevaleceu. Apesar da ênfase da Conferência no evitamento de reservas à Declaração por parte dos países participantes, considerando a gravidade da assimetria de gênero em todo o mundo, várias delegações não deixaram de apresentar suas restrições no relatório geral, muitas delas baseadas explícita ou implicitamente em princípios religiosos.

A delegação de Brunei Darussalam ressaltou os princípios islâmicos para apresentar suas reservas acerca de qualquer concepção de família que não seja aquela formada por pai, mãe e filhos, e também acerca do aborto, considerado ilegal no país. O país também se manifestou quanto à prática sexual entre adolescentes, que segundo sua compreensão, não deveria ser tolerada (UNITED NATIONS, 1996, p. 155-156).

Os princípios islâmicos também foram referidos pelos representantes do Irã (UNITED NATIONS, 1996, p. 163-164), do Iraque (p. 164), do Egito (p. 157158), do Kuwait (p. 165), da Líbia (p.165-166) e de outros países para afirmarem que temas como direitos sexuais e reprodutivos presentes na Plataforma de Ação devem ser aplicados no contexto exclusivo do casamento. Sobre o igual direito à herança para mulheres, a soberania da determinação da Sharia Islâmica foi afirmada.

Em relação à América Latina, a representação da Argentina repetiu seu posicionamento do Cairo, afirmando a família como união entre um homem e uma mulher que são os responsáveis pela criação e educação de seus filhos e filhas, bem como afirmando a não inclusão do aborto como método contraceptivo (UNITED NATIONS, 1996, p. 154-155).

Como a Argentina, a República Dominicana também se posicionou em relação ao aborto (UNITED NATIONS, 1996, p. 157). Seus representantes enfatizaram a concepção como o início da vida e sua completa rejeição a termos 
Religare, ISSN: 19826605, v.15, n.2, dezembro de 2018, p.483-504.

como interrupção da gravidez ou aborto ao se tratar de saúde reprodutiva ou direitos sexuais.

Evocando seus valores culturais e religiosos, a Guatemala juntou-se a outras delegações em sua reserva quanto ao uso do termo 'aborto", e reforçou sua posição de que a vida existe desde a concepção e deve ser protegida. A comissão fez também explícita menção ao termo "gênero", afirmando que de acordo com "critérios éticos, morais, legais, culturais e naturais do povo guatemalteco, a Guatemala interpreta o conceito de gênero somente como gênero feminino e masculino em referência a mulheres e homens" (UNITED NATIONS, 1996, p. 159).

O aborto também foi objeto das reservas de Honduras, reservas alegadamente culturais e religiosas (UNITED NATIONS, 1996, p. 162-163), bem como da Venezuela (p. 174-175). A Nicarágua apresentou restrições quanto ao aborto como método de controle de fertilidade, e explicitou sua concepção de família, entendida como união de um homem e uma mulher, ou chefiada por um deles ou composta pela família extensa (p. 168-169). Isso tudo para evitar interpretações de que o país estaria alinhado com concepções de família formada por casais não heterossexuais.

O Peru se posicionou na mesma direção (UNITED NATIONS, 1996, p. 169170). O Paraguai fez esse esclarecimento em relação ao uso do termo "gênero". Segundo seus representantes, a interpretação que os mesmos têm é de que gênero "se refere a ambos os sexos, homem e mulher". (UNITED NATIONS, 1996, p. 169)

Enquanto um bloco de países latino-americanos se alinhava com a Santa Sé em sua política contra os direitos sexuais e reprodutivos, o Brasil se distanciava dessa agenda, afirmando a importância de políticas voltadas para os direitos das mulheres. A agenda política do Itamaraty foi formulada por um comitê nacional criado especificamente para a IV Conferência - Comitê Brasileiro 
Religare, ISSN: 19826605, v.15, n.2, dezembro de 2018, p.483-504.

para a IV Conferência Mundial sobre a Mulher ${ }^{5}$ e com a participação organizada do movimento de mulheres ${ }^{6}$, e isso foi fundamental para o posicionamento oficial da delegação brasileira que aprovou, sem reservas, a plataforma de ação da Conferência de Pequim.

Em relação à Santa Sé, suas ponderações e reservas foram as mais longas. Após uma introdução reconhecendo a história de exclusão e opressão das mulheres e a semelhança entre o que propõe a Conferência e o que a Igreja Católica ensina, a delegação passou a listar os pontos que considerou questionáveis no documento. Dentre esses questionamentos, a Santa Sé entendeu que a Plataforma de Ação está dando "atenção desproporcional à saúde sexual e reprodutiva" (UNITED NATIONS, 1996, p. 160) de meninas e mulheres, e que a utilização de uma "linguagem ambígua" para se referir ao controle da fertilidade e para se referir à sexualidade, poderia sugerir o "endosso social para o aborto e a homossexualidade" (UNITED NATIONS, 1996, p. 160).

A delegação afirmou o exercício da sexualidade como exclusivamente dentro do casamento, e este entendido como a união entre um homem e uma mulher. Também afirmou que não reconhece o aborto ou quaisquer serviços nesse sentido como parte de planejamentos voltados para a saúde reprodutiva das mulheres. Na lista de reservas também foi incluída a negativa da contracepção e do uso de preservativos, mesmo como forma de prevenção da AIDS. A objeção de consciência por motivo de crença religiosa foi ressaltada como direito de profissionais da saúde.

A reserva da Santa Sé em relação ao termo "gênero" mereceu um tratamento separado. Ela argumentou haver uma compreensão na Plataforma de Ação que gerava alguma ambiguidade no uso do termo gênero, fazendo constar no relatório da Conferência a seguinte ressalva:

5 O comitê nacional era composto por representantes de Ministérios e outros órgãos governamentais, como o Conselho Nacional dos Direitos da Mulher. Também participaram do comitê mulheres do Fórum Nacional de Presidentas de Conselhos Estaduais da Condição e dos Direitos da Mulher.

${ }^{6}$ Articulação de Mulheres Brasileiras para Beijing. 
Religare, ISSN: 19826605, v.15, n.2, dezembro de 2018, p.483-504.

"O termo "gênero" é entendido pela Santa Sé como sendo fundamentado na identidade biológica sexual, isto é, masculino ou feminino. (...) Assim, a Santa Sé exclui interpretações dúbias baseadas em cosmovisões que afirmam que a identidade sexual pode ser indefinidamente adaptada para atender a novos e diferentes fins" (UNITED NATIONS, 1996, p. 162)

Para dar sustentação à ideia de que os diferentes papéis desempenhados por mulheres e homens estão baseados em uma suposta natureza feminina e masculina, a delegação evocou a afirmação do Papa João Paulo II no parágrafo 11 de sua "Carta às Mulheres", escrita no mesmo ano da Conferência de Pequim: "é possível acolher também, sem consequências desfavoráveis para a mulher, certa diversidade de papéis, na medida em que tal diversidade não é fruto de arbitrária imposição, mas brota da peculiaridade do ser masculino e feminino" (UNITED NATIONS, 1996, p. 162).

A IV Conferência Internacional sobre as Mulheres terminou, mas a articulação do Vaticano contra as plataformas de ação que derivaram especialmente dessa conferência e da Conferência do Cairo estava apenas começando. As conferências que se seguiram foram palco de disputas pela desconstrução dos consensos do Cairo e de Pequim. Segundo Sônia Corrêa (2015), à época coordenadora do GT População e Gênero da Associação Brasileira de Estudos Populacionais - ABEP, a estratégia do Vaticano e dos países islâmicos foi obstaculizar a adoção de novos documentos nas outras conferências, enfraquecendo assim as repercussões dos consensos do Cairo e de Pequim.

\section{A "ideologia de gênero" do Vaticano}

A organização da resistência aos avanços do Cairo e de Pequim foi coordenada pelo Vaticano, tendo sido assumida por setores conservadores da Igreja Católica em torno do que passaram a denominar de "ideologia de gênero". A Igreja Católica convocou conferências episcopais e produziu e financiou um 
Religare, ISSN: 19826605, v.15, n.2, dezembro de 2018, p.483-504.

sem número de publicações e orientações relacionadas ao tema desde a Conferência de Pequim em 1995.

Em 29 de junho de 1995, portanto, pouco antes da Conferência de Pequim, realizada em setembro, o Papa João Paulo II emitiu sua Carta às Mulheres, afirmando ter como objetivo que a Igreja ofereça,

a sua contribuição para a defesa da dignidade, do papel e dos direitos das mulheres, não só através da específica colaboração da Delegação oficial da Santa Sé nos trabalhos de Pequim, como também falando directamente ao coração e à mente de todas as mulheres (JOÃO PAULO II, 1995)

O Papa havia recebido a visita da secretária geral da Conferência de Pequim, Gertrude Mongella, e conforme ele mesmo afirma, lhe entregou uma mensagem contendo "os pontos fundamentais do ensinamento da Igreja" (JOÃO PAULO II, 1995) sobre as mulheres. Na Carta não há qualquer menção a gênero, mas o Papa evoca o "gênio da mulher", sugerindo uma natureza feminina pautada no serviço e na maternidade, reforçando as representações dominantes de gênero. Não é sem razão que o termo "serviço" aparece 15 vezes no documento, e os termos "mãe" e "maternidade", somam dez menções.

Talvez um dos trechos mais polêmicos da Carta, tenha a ver com o tema do aborto. O Papa exalta

as mulheres que, com amor heróico pela sua criatura, carregam uma gravidez devida à injustiça de relações sexuais impostas pela força; e isto não só no quadro das atrocidades que, infelizmente, se verificam nos contextos de guerras, ainda tão frequentes no mundo, mas também nas situações de bem-estar e de paz, não raro viciadas por uma cultura de permissivismo hedonista, na qual prosperam facilmente também tendências de machismo agressivo (JOÃO PAULO II, 1995).

Uma das pautas da Conferência de Pequim e das que a antecederam foi justamente a dos direitos reprodutivos, tendo sido a descriminalização do aborto um dos pontos mais controversos em todas elas. Conforme vimos ao tratar das 
Religare, ISSN: 19826605, v.15, n.2, dezembro de 2018, p.483-504.

conferências do Cairo e de Pequim, as reservas colocadas pela Santa Sé e por países nos quais a Igreja Católica tem forte ingerência, foram não somente mas, especialmente, acerca dessa temática. Exaltar as mulheres que levam a termo uma gravidez indesejada, produto de estupro, e identificar o aborto como "um pecado grave" (JOÃO PAULO II, 1995), já antecipa o posicionamento do Vaticano e de países com ele alinhados acerca dos direitos reprodutivos das mulheres.

Na Carta o Papa não faz menção a gênero, a não ser para se referir ao "gênero humano". Essa abordagem se revelará necessária para a Igreja Católica logo após a Conferência de Pequim, em que se avançou um pouco mais na plataforma de ação para o enfrentamento da assimetria de gênero, em especial quanto aos direitos sexuais e reprodutivos, contrariando os objetivos reguladores da Santa Sé.

A oposição a gênero se organizou rapidamente por parte de alguns representantes que se manifestavam contrários aos avanços em relação aos direitos das mulheres e das populações LGBT. Um novo argumento para obstaculizar a reivindicação pelos direitos das mulheres começou a ser tecido. Lideranças religiosas e políticas iniciaram a urdidura de um processo que viria a ser conhecido como "luta contra a ideologia de gênero" em oposição ao gender mainstreaming tecido nas conferências do Cairo e de Pequim, e esse movimento obteve muitas adesões ao longo dos anos, espalhando-se por diferentes países, obstaculizando o enfrentamento das desigualdades de gênero ${ }^{7}$.

O discurso antigênero da Igreja Católica e a construção da noção de "ideologia de gênero" têm como estratégia a desqualificação da ideia de empoderamento e autonomia das mulheres, e responsabilizam organizações internacionais que apoiam a causa das mulheres, de serem contra a família e a maternidade.

\footnotetext{
${ }^{7}$ A respeito de como o discurso contra a "ideologia de gênero" foi utilizado para obstaculizar o debate sobre gênero na educação brasileira ver: NUNES, Maria José Rosado (2014); SOUZA, Sandra Duarte de (2014).
} 
Religare, ISSN: 19826605, v.15, n.2, dezembro de 2018, p.483-504.

Em 1997, portanto, dois anos após a conferência de Pequim, o jesuíta monsenhor Michel Schooyans, que foi professor na PUC-SP na década de 1960, publicou o livro intitulado L'Évangile face au désordre mondial, que foi traduzido para o português no ano 2000. O então cardeal Joseph Ratzinger fez o prefácio do livro no qual afirmava que as conferências do Cairo e de Pequim promovidas pela ONU apresentavam uma filosofia que

Determina os limites do procurado bem-estar a partir dos limites dos meios próprios para o alcançar (...) O carácter típico desta nova antropologia, concebida para fundamento da Nova Ordem Mundial, manifesta-se sobretudo na imagem da mulher, na ideologia do "Women's empowerment", proposta por Pequim. O fim em vista é a auto-realização da mulher, que encontra os seus principais obstáculos na família e na maternidade. Assim, a mulher deve ser libertada sobretudo do que a caracteriza e lhe dá nada mais que a sua especificidade: esta é chamada a desaparecer diante de uma "Gender equity and equality", diante de um ser humano indistinto e uniforme, em cuja vida a sexualidade não tem outro sentido senão o de uma droga voluptuosa, de que a gente se pode servir seja lá como for (SCHOOYANS, 2000, p. 8).

Ratzinger ironiza a pauta que visa a adoção de políticas sexuais e reprodutivas que promovam maior autonomia para as mulheres e que lhes assegurem a possibilidade de viver com dignidade, liberdade e equidade, e sugere que a ONU tem participação ativa no estabelecimento dessa "Nova Ordem Mundial". A construção de uma relação de oposição entre empoderamento das mulheres e defesa da família e da maternidade é explícita. Esse prefácio já anuncia o que está por vir no livro de Schooyans, que se dedica a desqualificar as iniciativas de organizações internacionais que desenvolvem ou apoiam projetos voltados para a saúde reprodutiva e sexual das mulheres e que visam a redução das assimetrias de gênero. Segundo Rogério Diniz Junqueira (2017, p. 33), esse é talvez o primeiro livro a utilizar a expressão "ideologia de gênero" para se referir a uma suposta conspiração que envolveria a parceria de mecanismos internacionais e minorias sexuais subversivas visando o fim da 
Religare, ISSN: 19826605, v.15, n.2, dezembro de 2018, p.483-504.

família. A expressão aparece dessa forma já no subtítulo do capítulo II: “A ideologia do gênero" (SCHOOYANS, 2000, p. 53). O título do capítulo também sugere esse enfoque: "A coligação ideológica do gênero" (SCHOOYANS, 2000, p. 45).

Se o livro de Schooyans é um dos pioneiros a cunhar a expressão “ideologia de gênero", é em 1998 que, pela primeira vez, ela é mencionada em um documento eclesiástico. O bispo auxiliar de Lima, monsenhor Óscar Alzamora Revoredo, elaborou a nota da Conferência Episcopal do Peru, intitulada La ideologia de género: sus peligros y alcances. Seu texto tomou como base o artigo de Dale O'Leary, intitulado The Gender Agenda: Redefining Equality (1997). O’Leary é ligada à Opus Dei e tem diversos escritos antifeministas.

A expressão "ideologia de gênero" dá nome à nota da Conferência Episcopal, mas no corpo do documento, a expressão preferencial de Revoredo é "feminismo de gênero", tomando emprestada a expressão cunhada pela filósofa e escritora estadunidense Christina Hoff Sommers, em seu livro Who stole feminism? (1994), que afirma ser esse um tipo de feminismo que enxerga os homens como inimigos opressores. $\mathrm{O}$ monsenhor menciona trechos fragmentados de teóricas feministas para validar seus argumentos acerca da “ameaça de gênero" para o mundo. Ele cita diversas teóricas às quais denomina de "feministas de gênero". Judith Butler, Ann Ferguson, Nancy Folbre, Heidi Hartmann, Susan Okin, Alison Jagger, Nancy Chodorow, Rebecca Cook, Carol Christ, e as teólogas Elizabeth Schüssler Fiorenza, Joanne Brown e Carole Bohn, são "acusadas" por Revoredo como "feministas de gênero", estando a serviço da destruição da família, da cultura e da religião. Ele, inclusive, se refere a uma suposta articulação de ONGs feministas que visam o "ataque à religião". Segundo o bispo auxiliar (1998, p. 606),

Numerosas ONG acreditadas ante la ONU se han empeñado en criticar a quienes ellos denominan "fundamentalistas" (cristianos, católicos, evangélicos y ortodoxos judíos y musulmanes, o 
Religare, ISSN: 19826605, v.15, n.2, dezembro de 2018, p.483-504.

cualquier persona que rehúse ajustar las doctrinas de su religión a la agenda del "feminismo de género").

Nos anos seguintes, o Pontifício Conselho para a Família emitiu outros documentos enfatizando o perigo da "ideologia de gênero" para a família e o casamento. A mobilização da Cúria Romana para a produção de material antigênero por teólogos e teólogas, demonstra o empenho da Igreja Católica em se colocar em oposição a quaisquer políticas voltadas para os direitos reprodutivos e sexuais. Esse é o objetivo do Lexicon: termos ambíguos e discutidos sobre família, vida e questões éticas (PONTIFICIO Conselho para a Família, 2003), encomendado pelo Conselho, que à época era presidido pelo cardeal Alfonso López Trujillo. Para Junqueira (2017, p. 39), “o Lexicon ataca todo um conjunto de valores e referências que começou a se consolidar, sobretudo em sociedades mais avançadas e secularizadas e que, ao se afirmar nas conferências da ONU, dissemina-se pelo mundo".

Óscar Alzamora Revoredo, Michel Schooyans e nada menos que a Cúria Romana, dentre outros setores da Igreja Católica, contribuíram para a disseminação de um pânico generalizado acerca de gênero, fazendo proliferar manifestações contrárias a quaisquer iniciativas voltadas para o incremento de políticas de gênero, impactando severamente os já precários direitos de mulheres e LGBTs em todo o mundo. Isso teve consequências sobre a proposição e implementação de políticas públicas voltadas para o enfrentamento da violência contra as mulheres, para a redução das assimetrias de gênero, para a afirmação dos direitos sexuais e reprodutivos etc.

\section{Considerações finais}

As reservas da Santa Sé às plataformas de ação derivadas das conferências internacionais sobre desenvolvimento populacional e sobre a mulher, e as publicações produzidas especialmente ao longo das décadas de 1990 e 2000, não se tratam apenas de manifestações pontuais acerca do tema. A Igreja Católica planejou, financiou e executou seu projeto antigênero, minando o consenso 
Religare, ISSN: 19826605, v.15, n.2, dezembro de 2018, p.483-504.

internacional que foi construído a passos lentos nas conferências da ONU, influenciando a política internacional e as políticas locais.

A produção e disseminação do pânico moral (Stanley COHEN, 2002) têm servido aos propósitos da Igreja Católica ao longo dos séculos. A crise de autoridade vivida pela Igreja na contemporaneidade, a perda do seu poder regulador sobre as instituições sociais e mesmo sobre os sujeitos religiosos, a levou a se mobilizar mais uma vez em torno daquilo que lhe é mais caro e que permite mobilizar com mais eficácia: o sexo. É pelo sexo que o recrutamento dos "defensores da família, da moral e dos bons costumes" acontece. É pela ativação de uma imaginação fantasmagórica que a mensagem antigênero é plasmada de tal forma que seu caráter misógino, homofóbico, e antidemocrático parece não importar. É pelo sexo que a Igreja Católica tem conseguido maior ingerência na coisa pública, maior peso na negociação política, incluindo-se aí os processos legislativos e jurídicos. É pelo sexo que as mulheres estão sendo deixadas de fora das políticas para as mulheres.

Conforme escrevi em outra ocasião, há que se discutir "a ação política de grupos religiosos hegemônicos no processo de definição das fronteiras do público, [que deixam] "de fora" as mulheres, não importa se católicas, evangélicas, de outras religiões ou sem religião". (SOUZA, 2015, p.89-90)

Nas disputas por legitimidade política a Igreja Católica engendrou sua política antigênero. A desqualificação de gênero e a construção da ideia das feministas como inimigas a serem combatidas, teve, tem e terá impacto direto sobre os direitos e consequentemente sobre a vida das mulheres e da população LGBT, pois as políticas públicas voltadas para esses segmentos dependem especialmente da mobilização dos movimentos feministas e LGBT, que têm sido sistematicamente "lembrados" por setores conservadores vários, incluam-se aqui grupos religiosos diversos, da ilegitimidade de suas demandas.

\section{Referências}


Religare, ISSN: 19826605, v.15, n.2, dezembro de 2018, p.483-504.

ALVES, José Augusto Lindgren. A agenda social da ONU contra a desrazão "pósmoderna". Revista Brasileira de Ciências Sociais - RBCS, vol. 11, n. 30. São Paulo, 1996, p. 63-81.

ALZAMORA REVOREDO, Oscar. La ideologia de género: sus peligros y alcances. Lima: Comisión Ad Hoc de la Mujer; Comisión Episcopal de Apostolado Laical. Conferencia Episcopal Peruana, 1998.

BARSTED, Leila Linhares, HERMAN, Jacqueline. As mulheres e os direitos civis: traduzindo a legislação com a perspectiva de gênero. Rio de Janeiro: CEPIA, 1999. CHALLITA, Mansour (trad.) O Alcorão. Rio de Janeiro: Associação Cultural Internacional Gibran.

COHEN, Stanley. Folk devils and moral panics: the creation of the mods and rockers. London: Routledge, 2002.

CORRÊA, Sônia. Cairo+10: a controvérsia que não acabou. Associação Brasileira de Estudos Populacionais - ABEP, 2015. Disponível em: http://www.abep.org.br/publicacoes/index.php/livros/article/viewFile/122/120 Acesso em: 16 ago. 2018.

CONSEJO NACIONAL DE POBLACIÓN. Memoria de la Conferencia Internacional de Población, México, D.F., 6-14 de agosto de 1984.

FAVIER, Anthony. La réception catholique des études de genre: une approche historique, en contexte francophone. Hal, Lille, set. 2012. Disponível em: https://halshs.archives-ouvertes.fr/halshs-00765786/document . Acesso em: 07 set. 2018.

FROSSARD, Heloisa (Org.). Instrumentos Internacionais de Direitos das Mulheres. Secretaria Especial de Política para as Mulheres, Brasília, 2006.

JOÃO PAULO II. Carta do Papa João Paulo II às Mulheres. Libreria Editrice Vaticana, 1995. Disponível em: https://w2.vatican.va/content/john-paulii/pt/letters/1995/documents/hf_jp-ii_let_29061995_women.html Acesso em: 27 dez. 2018.

JUNQUEIRA, Rogério Diniz. "Ideologia de gênero": a gênese de uma categoria política reacionária - ou: a promoção dos direitos humanos se tornou uma "ameaça à família natural"? In: RIBEIRO, Paula Regina Costa e MAGALHÃES, Joanalira Corpes. Debates contemporâneos sobre Educação para a sexualidade. Rio Grande: Ed. da FURG, 2017, p. 25-52.

NACIONES UNIDAS. Informe de la Conferencia Mundial de Población. México, CEPAL, $1975 . \quad$ Disponível em: https://repositorio.cepal.org/bitstream/handle/11362/21970/S7500346_es.pdf?seq uence=2\&isAllowed=y Acesso em: 05 jul. 2018.

NUNES, Maria José Rosado. Gênero: uma questão incômoda para as religiões. In: SOUZA, Sandra Duarte e SANTOS, Naira Pinheiro (orgs.). Estudos Feministas e Religião: tendências e debates. Curitiba. Prismas, 2014, p. 129-147.O'LEARY, Dale. The Gender Agenda: Redefining Equality. Paperback, Nov. 1997.

ONU. Relatório da Conferência Internacional sobre população e Desenvolvimento - Plataforma de Cairo. Fundo de População das Nações Unidas 
Religare, ISSN: 19826605, v.15, n.2, dezembro de 2018, p.483-504.

(UNFPA Brasil), $1994 . \quad$ Disponível em: http://www.unfpa.org.br/Arquivos/relatorio-cairo.pdf Acesso em: 28 ago. 2018. ONU MULHERES. Declaração e Plataforma de Ação da IV Conferência Mundial sobre a Mulher. Pequim, 1995. Disponível em: http://www.onumulheres.org.br/wpcontent/uploads/2014/02/declaracao_pequim.pdf Acesso em: 08 jul. 2018. PONTIFÍCIO Conselho para a Família. Família, matrimônio e "uniões de fato". Cidade do Vaticano, 26 jul. 2000. Disponível em: http://www.vatican.va/roman_curia/pontifical_councils/family/documents/rc_p c_family_doc_20001109_de-facto-unions_po.html . Acesso em: 07 set. 2018.

PONTIFÍCIO Conselho para a Família. Lexicon: termos ambíguos e discutidos sobre família, vida e questões éticas. CNBB, 2012.

SCHOOYANS, Michel. O Evangelho perante a desordem mundial. Lisboa, Grifo, 2000.

SOUZA, Sandra Duarte de. "Não à ideologia de gênero". A produção religiosa da violência de gênero na política brasileira. Estudos de Religião, v. 28, n. 2, 2014, p. 188-204.

SOUZA, Sandra Duarte de. Secularização, laicidade e espaço público: uma conversa sobre gênero, religião e política no Brasil contemporâneo. In: Religião e espaço público: cenários contemporâneos. São Paulo, Paulinas, 2015, p. 68-92.

UNITED NATIONS. Report of the Fourth World Conference on Women. United Nations - New York, 1996. Disponível em: http://www.un.org/womenwatch/daw/beijing/pdf/Beijing\%20full\%20report\%20 E.pdf acesso em: 10 jun. 2018.

UNITED NATIONS DEVELOPMENT PROGRAMME. Gender Inequality Index. In: Human Development Reports, 2018. Disponível em: http://hdr.undp.org/en/content/gender-inequality-index-gii Acesso em: 26 dez. 2018.

UN WOMEN. The Four Global Womens' Conferences 1975 - 1995: Historical Perspective. Women 2000. Gender Equality, Development and Peace for the Twenty First Century. New York, 5-9 June 2000. Disponível em: http://www.un.org/womenwatch/daw/followup/session/presskit/hist.htm Acesso em: 05 jul. 2018.

Recebido em 16-10-2018. Aprovado em 20-01-2019. 